LITERATURA 



\section{ANDIRA WATSON EN CLAVE DE AMISTAD Y POESÍA CON SHIRLEY CAMPBELL: LA “SORORIDAD” ENTRE POETAS AFROCARIBEÑAS}

Jorge Chen Sham

\section{(9) $(1) \Theta \Theta$}

Doi: https://doi.org/10.15517/rfl.v46i2.43633

URL: https://revistas.ucr.ac.cr/index.php/filyling/index 



\title{
ANDIRA WATSON EN CLAVE DE AMISTAD Y POESÍA CON SHIRLEY CAMPBELL: LA "SORORIDAD” ENTRE POETAS AFROCARIBEÑAS
}

\author{
ANDIRA WATSON IN THE KEY OF FRIENDSHIP AND \\ POETRY WITH SHIRLEY CAMPBELL: "SORORITY" \\ BETWEEN AFRO-CARIBBEAN POETS
}

Jorge Chen Sham

\begin{abstract}
RESUMEN
¿Qué sucede cuando un poeta le dedica públicamente un poema a otro compañero de oficio? Este artículo responde revisando la tradición clásica que, desde la conciencia de una fraternidad entre "almas gemelas", hace del intercambio de afectos y de sentimientos, la expresión de unas aspiraciones comunes. Realizar una dedicatoria pública subraya unos lazos ideológicos y estilísticos para marcar una agenda política y ética. La poeta nicaragüense Andira Watson lo realiza al hacer un homenaje público a su colega costarricense Shirley Campbell. Se trata de un contexto en donde se pone de relieve la identidad afrocaribeña, con el fin de mostrar su "sororidad" asumida y reivindicada.

Palabras clave: Andira Watson; Shirley Campbell; poesía centroamericana; dedicatoria pública; negritud.
\end{abstract}

\begin{abstract}
What happens when a poet publicly dedicates a poem to another poet? This article answers this question by reviewing the classic tradition that, from an awareness of a fraternity between "soul mates", makes the exchange of affections and feelings the expression of shared aspirations. Carrying out a public dedication highlights ideological and stylistic ties to create a political and ethical agenda. Nicaraguan poet Andira Watson does this by making a public tribute to her Costa Rican colleague Shirley Campbell. It is a context in which the Afro-Caribbean identity is highlighted in order to demonstrate her assumed and vindicated "sorority".

Keywords: Andira Watson; Shirley Campbell; Central American poetry; public dedication; blackness.
\end{abstract}

En clave metapoética, la conciencia del poeta deriva en varios tópicos que hablan de la exaltación, "por su oficio y por su arte" (Curtius, 2004, p. 680), del trabajo de la escritura; entre ellos se encuentra la amistad entre poetas, en donde se muestra el orgullo de pertenecer a un selecto grupo de seres alados que cultivan la palabra y la pluma y que, a través de ellas, pretenden inmortalizarse gracias a la fama y al buen nombre, pues el poeta "logra para sí mismo fama inmortal" (Curtius, 2004, p. 669). Así, el intercambio y el trato entre poetas se valorizan para que sea un rasgo conspicuo de esas almas elevadas y que se hermanan en el arte.

Dr. Jorge Chen Sham. Profesor de la Escuela de Filología, Lingüística y Literatura. Universidad de Costa Rica. San José, Costa Rica. Miembro correspondiente de la Academia Nicaragüense de la Lengua y la Academia Norteamericana de la Lengua Española. Correo electrónico: jorgechsh@yahoo.com

Recepción: 09- 04- 19

Aceptación: 12- 08- 20 
De esta forma, las ventajas de la amistad entre poetas superan lo que Sánchez-Blanco (1992) denominó, en pleno siglo ilustrado, como "la estimación subjetiva de la persona" (p. 100), de esos honores públicos y protocolarios que otorgaban el estatus simbólico y que, durante el siglo XIX, desembocaban en el cuestionamiento tanto del dinero y de las leyes del mercado que intervenían en la literatura de quioscos y de la prensa escrita, así como se decantaba hacia el desprecio al mundo burgués, “asservi aux soucis vulgaires du négoce, et le 'peuple' livré à l' abêtissement des activités productives" (Bourdieu, 1997, p. 101) ${ }^{1}$. Estas relaciones patentizan una nueva pertenencia y aspiración de hermandad bajo "l' ostentation de la différence [...]; c' est aussi et surtout une posture éthique et esthétique tout entière tendue vers une culture (et non un culte) du moi, c' est-à-dire vers l' exaltation et la concentration des capacités sensibles et intellectuelles" (Bourdieu, 1997, p. 134)2. Se trata, entonces, de ponderar la amistad como el lugar de encuentro entre el afecto personal y la comunión de altos valores espirituales o artísticos, de modo que esta elección sea la consecuencia de sacar a relucir ciertas relaciones intersubjetivas y de elección personal.

Como analiza Curtius (2004), estas afinidades se realizaban con el fin de valorar la conciencia del oficio de poeta que se fue perfilando desde la Edad Media latina hasta el Renacimiento europeo. Las reflexiones sobre la amistad se concentraron tanto en la inspiración del poeta como en la "inmortalización" que suponía este digno y loable oficio en apego a la tradición de sus "predecesores" (p. 680), al tiempo que privilegiaba el arte más excelso en las concepciones del Antiguo Régimen, la poesía y el poeta. Pero, a partir del siglo XVIII, estas relaciones se decantaban más bien hacia la valorización de un afecto y de un pensamiento común y solidario, porque "el placer de la amistad representa[ba] la esperanza de dar a la existencia un contenido y un contexto de alegría" (Sánchez-Blanco, 1992, p. 113). La afinidad de las almas gemelas entre poetas o de la amistad entre poetas, como también se le denomina, tiene mucho que ver ahora, no solo con un intercambio de afectos y de sentimientos, sino también con unas aspiraciones comunes que expresan lazos ideológicos y estilísticos.

En el ámbito de la producción literaria de mujeres, deben plantearse los retos que significa tanto invadir un terreno propio del mundo masculino como transgredir las actividades reservadas a la mujer, porque tomar la pluma y esgrimirla en público obligan no solo a diferenciarse, sino también a potenciar la conciencia de su excepcionalidad; Susan Kirkpatrick (1989) aborda cómo la renovación del potencial femenino hacia la creación se hace bajo el reconocimiento de esas pioneras que, como la poeta Safo, expresaban la convicción de una sensibilidad especial y extraordinaria, "como elementos de una tradición que autorizaba y conformaba la voz femenina en la poesía” (p. 86). De esta manera, las poetas y las narradoras románticas construyen, más que un sentimiento de rivalidad, una afinidad que las conduce, por un lado, hacia la solidaridad, y por otro, hacia la reivindicación de su acceso a la cultura en general y no solamente a la letrada: "el derecho de la mujer a la actividad intelectual y a la expresión literaria” (Kirkpatrick, 1989, p. 90), dentro de una "hermandad lírica” (Kirkpatrick, 1989, p. 84), es decir, de afinidad también entre almas sensibles pero que reconocen una

\footnotetext{
1 "dominado por las preocupaciones vulgares de los negocios, mientras el pueblo se consumía en el embrutecimiento de las actividades productivas".

2 "la ostentación de la diferencia [...]; es también y ante todo una postura ética y estética totalmente consagrada a la cultura (y no un culto) del yo, es decir, a la exaltación y la concentración de las capacidades sensibles e intelectuales".
} 
vocación fuera de "la moda del tiempo". Observemos cómo Kirkpatrick (1989) utiliza aquí el término "hermandad" más neutro e histórico para no cometer un anacronismo que, desde nuestro punto de vista es acertado, porque la "sororidad" implica otros presupuestos teóricos e ideológicos, tal y como veremos más adelante.

Ahora bien, en términos contemporáneos y para diferenciar esta manera de concebir la amistad de las antiguas concepciones del tópico clásico según Curtius (2004), las afinidades conducen a manifestar una agenda política y ética, que se asume abiertamente a través de una dedicatoria pública en este caso. Sin embargo, hay otras formas de identificación y de mostración de las afinidades en las prácticas literarias a partir del siglo XIX, cuando la imprenta masifica el libro y la conciencia de la autoría se vuelve reconocimiento, sobre todo en poesía. Tenemos en nuestra práctica actual, sobre todo a partir del siglo XIX, las siguientes opciones: a) un poeta puede imitar o parafrasear el poema de otro colega de oficio y deja constancia de ello ya sea en el título o en la dedicatoria; b) un poeta escribe un ars poetica exhibiendo sus fuentes y sus lecturas a modo de relato de iniciación o aprendizaje y allí cita o menciona a sus autores elegidos; c) un poeta le puede dedicar públicamente un poema a otro sin ninguna explicación directa. Esta tercera vía es la que analizaremos a continuación. El poeta se dirige a otro compañero de oficio y le realiza un homenaje público, bien sentido y fuera del ámbito personal para volverse público y, con esta finalidad, le dedica públicamente el poema.

Desde el trabajo seminal de Gérard Genette sobre las formas paratextuales, aquellas que rodean al libro y le permiten circular socialmente, sabemos de la importancia y significación de las dedicatorias, sobre todo la dedicatoria de la obra, en la que se hace un homenaje a una persona concreta. Este homenaje y ofrecimiento público, que es la "dedicación", concierne propiamente a la realidad ideal de la producción literaria y a la manera en que el escritor se inserta en el mundo y se enfrenta a él, al demostrar y exhibir "une relation, intellectuelle ou privée, réelle ou symbolique, et cette affiche est toujours au service de l'oeuvre, comme argument de valorisation ou thème de commentaire" (Genette, 1987, p. 126) ${ }^{3}$. De esta manera, el autor exhibe sus inclinaciones personales y sus afectos se hacen públicos.

En el caso por estudiar, en su más reciente y panorámico estudio y antología sobre las poetas centroamericanas contemporáneas, Magda Zavala presenta a una de las poetas más importantes del actual Caribe nicaragüense, Andira Watson (1977), con un poema intitulado "Rotundamente negra", poema inédito al momento de aparición de este libro en 2011. El poema lleva una dedicatoria: "A la poeta Shirley Campbell Barr"4 y esto no puede pasar desapercibido, por dos motivos: a) se identifica a Shirley Campbell Barr como poeta, y b) dentro de la estructura comunicacional del poema, el yo poético se dirige a un tú poético con el nombre de Shirley. De esta manera, se comprueba la relevancia de la dedicatoria del poema, por cuanto se hace un homenaje a una poeta y ella entra en juego y en un diálogo que recuerda la identificación empática y una vinculación hacia un proceso comunicativo de "apelación comunicacional" (Castilla del Pino, 2000, p. 71) tanto con este destinatario interno enunciado en la dedicatoria, como con el lector, quien, forzosamente, irá a buscar la clave de la dedicatoria, o al menos saber algunas señas de identidad de la persona dedicada.

3 "una relación, intelectual o privada, y este alarde está siempre al servicio de la obra, como argumento para valorizar o tema de un comentario".

4 Las cursivas son del texto. Cito el poema por la antología de Zavala (2011). 
Todo lo anterior permite identificar, como señalaba Genette (1987), varias relaciones que se buscan establecer desde el punto de vista paratextual: en primer lugar, la relación intelectual y privada, por cuanto Shirley Campbell (n. 1965) es una poeta "afrodescendiente" costarricense que publica primero el poemario Naciendo (1988), con una temática que habla de sus raíces afrocaribeñas y de la identidad femenina en relación con el color de la piel. Para Dorothy E. Mosby (2003), Campbell y otras poetas de su generación tales como Delia MacDonald, "attempt to call the attention of their compatriots and assert their undeniable blackness through a reconnection with history in order to affirm their sense of belonging to the nation" (p. 168) $)^{5}$. Andira Watson, otra poeta afrodescendiente, le realiza un homenaje dedicándole un poema y, a la vez, establece una comunicación entre ellas al reclamar una "hermandad"; volveremos sobre este elemento de comunidad ideológica más adelante.

En segundo lugar, se trata de una relación real y también simbólica, porque además de esa sintonía afectiva, que la amistad engalana entre ellas, hay una filiación ideológica que las reúne y las convoca por medio de este poema de Watson. A esto responderá este artículo. Pero, ¿de qué escribió Shirley Campbell Barr, para que Watson ahora le haga no solo un homenaje, sino que también dialogue con ella? El poemario Naciendo (1988) lo publica Campbell de una manera un poco artesanal, fuera de los circuitos editoriales establecidos, lo que habla de las dificultades de publicación en esos años para esta poeta. Sin embargo, su consagración editorial le viene con Rotundamente Negra y otros poemas, editado primeramente por la Editorial Torremozas en 2004, la editorial de mujeres más prestigiosa del mercado hispánico. Su segunda edición se realizó luego en Costa Rica, en el año de 2006 ${ }^{6}$. En tanto forma de intitular un libro, llama la atención que sea el nombre de la "Primera sección" el que aporte el título a todo el poemario, en una relación de metonimia de la parte por el todo. La carga declarativa y programática se encuentra en el "Poema 13" de esta "Primera sección" para que en el título epónimo resuene el adverbio "rotundamente", como un grito de rebelión y de afirmación étnica. Veamos el poema de Campbell:

Me niego rotundamente

a negar mi voz,

mi sangre y mi piel

y me niego rotundamente

(v. 5) a dejar de ser yo,

a dejar de sentirme bien

cuando miro mi rostro en el espejo

con mi boca

rotundamente grande

(v. 10) y mi nariz

rotundamente hermosa

y mis dientes

rotundamente blancos

y mi piel

(v. 15) valientemente negra.

Y me niego categóricamente

a dejar de hablar

mi lengua, mi acento y mi historia

y me niego absolutamente

$5 \quad$ "tratan de llamar la atención de sus compatriotas y hacer valer su innegable negritud a través de una reconexión con la historia, con el fin de afirmar su sentido de pertenencia a la nación".

$6 \quad$ Cito a Campbell por esta segunda edición del poemario. 
(v. 20) a ser parte de los que callan

de los que temen

de los que lloran

porque

me acepto

(v. 25) rotundamente libre

rotundamente negra

rotundamente hermosa. (2006, p. 89).

Llama poderosamente la atención el uso del adverbio "rotundamente", repetido de forma constante no solo como leitmotiv, sino también en equivalencia con otros adverbios en -mente, tales como "categóricamente", "valientemente" o "absolutamente", para dar esa idea de una afirmación enfática y vehemente. El adverbio viene del adjetivo 'rotundus', "redondo [y] completo, perfecto, acabado" (Diccionario ilustrado Latino-español, Español-latino, 1980, p. 443); mientras que el verbo proporciona la idea de completar un movimiento circular y acabado en su sentido literal. En español acaba expresando también una argumentación acabada y completa, lo cual subraya el significado del adverbio en el DRAE (2014): "De un modo claro y preciso, terminantemente. Que no deja lugar a duda". De esta manera, el título del poema da cuenta de la afirmación del color negro, para luego trasladarse al nivel del color de la piel, lo cual identifica el cuerpo que así se adjetiva; pero el cuerpo aquí tiene una marca de femenino ("negra'), gracias a lo cual quien aquí se describe y se percibe como "rotundamente negra", muestra una autoidentificación y una reivindicación de su propio color de piel y, de rebote, de su cuerpo femenino. Tal encadenamiento sinecdótico, porque trabaja siempre con las relaciones entre la parte y el todo, desemboca en la marcación de su cuerpo (movimiento giratorio) y de su radical diferencia étnica y biológica (afirmación categórica).

Ahora bien, si el título del poemario se presenta como una toma de conciencia racial y genérica, es porque es el paso previo para el distanciamiento que se proclama en la primera unidad del poema. La forma verbal seleccionada por Campbell no es inocente; el "Me niego rotundamente" (vv. 1 y 4), luego retomado con una variación en los versos "Y me niego categóricamente" (v. 16) y "y me niego absolutamente" (v. 19); todos ellos entran en una estructura distributiva y de alternancia de la siguiente manera:

"Me niego rotundamente" (v. 1) = "Y me niego categóricamente" (v. 16)

"Me niego rotundamente" (v. 4) = "y me niego absolutamente" (v. 19)

Se trata de buscar la eufonía y la repetición de los adverbios en -mente, proporcionan un ritmo y un tono concluyente con la introducción de la conjunción copulativa "y". Por cierto, se repite cuatro veces el verbo dentro de una estructura acabada y perfecta con el número 4, abarcando el movimiento corporal y argumentativo de todo el poema, mientras el verbo "negarse a" resuena en una voz poética que se empodera conscientemente de la palabra, pues "turns to herself for the strength to continue the battle to vindicate the history of her people" (Mosby, 2003, p. 206) ${ }^{7}$. Mosby tiene razón en plantear que a través de su voz personal se oyen otras: no es solamente ella la que rehúsa callarse para no aceptar más su condición subalterna.

A la luz de lo anterior volvamos al inicio del poema. La doble negación se transforma, entonces, en afirmación de un programa ético y político: "Me niego rotundamente / a negar mi voz, / mi sangre y mi piel” (vv. 1-3). El verbo con el que se inicia el poema es sintomático de esa

7 "se vuelve hacia sí misma por la fuerza para continuar la batalla de reivindicar la historia de su pueblo". 
toma de conciencia y de liberación; con "negarse a" no solo la voz poética muestra su oposición a reconocer algo instituido o algo sancionado por la tradición, sino también su rechazo a seguir transmitiéndolo. En este caso, hay un gesto de rebelión que encierra la enumeración "mi voz / mi sangre y mi piel", para que estos elementos metonímicos dibujen primeramente el cuerpo. Así, la afirmación del color de la piel se enarbola como valoración positiva, para que se explicite como un elogio de sí misma y sea visto luego como marca de rebeldía. Tal y como se reafirma, el acto discursivo que se realiza no es tanto "negar" sino "proclamar", porque la "positividad de la creencia -reforzada además y frente a un reconocimiento (ver) negativo- organiza el poema" (López-Casanova, 1994, p. 77) y marcaría así la función modal del acto comunicativo: al negar, reafirmo mi color de piel. Si "rotundamente" se refiere literalmente al movimiento circular, este se realiza primero sobre el cuerpo que se describe a través de la metáfora del espejo, la cual apela directamente hacia la reivindicación de la identidad; la voz poética se define con unos rasgos que el retrato femenino de la amada había sancionado ya desde la poesía petrarquista, en donde se ponderaba la belleza ideal femenina equilibrada, armoniosa y sobre todo de blancura, "en torno a una imaginería que combinaba la pedrería suntuaria y la flora con una concreta variedad cromática y plástica" (Matas Caballero, 2001, p. 78); pero que en el poema de Campbell se neutralizan con la "boca" y la "nariz" desproporcionadas que no corresponden a un ideal de belleza simétrica y se actualizan con la "piel / valientemente negra":

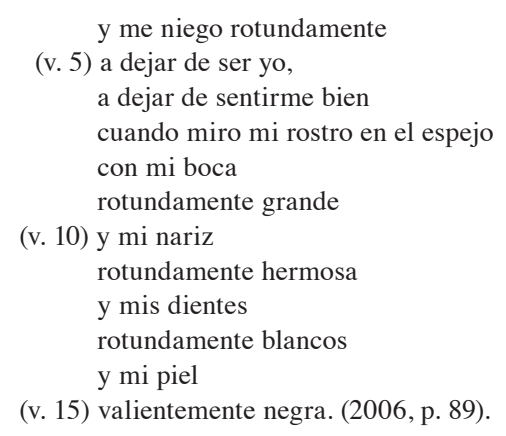

Tres veces se repite el adverbio "rotundamente" relacionado con un adjetivo para describir partes de la cara, a saber "rotundamente grande" (v. 9), "rotundamente hermosa" (v. 11) y "rotundamente blancos" (v. 13); pero inesperadamente en lo que podría ser la cuarta vez que se hiciera su uso, el adverbio cambia a "valientemente" en una alusión estratégica para connotar a la piel. No es casual que sea aquí la piel la que no lleve el adverbio de marras: primeramente, se subraya el ámbito personal y el posicionamiento individual, con el fin de evocar, en un segundo nivel, las vicisitudes y la rebeldía de esa piel "negra" que reclama su lugar en una historia colectiva y pretende no guardar silencio o callar más un sufrimiento.

La toma de conciencia inicial sobre el cuerpo es el preámbulo para la afirmación identitaria que encierra el "dejar de ser yo" (v. 5), de manera que el movimiento que dibuja el poema de Campbell es aceptar su cuerpo, para luego diseñar una estrategia de autoafirmación étnica, porque conlleva la conciencia de la historia de subordinación y de la desigualdad racial. La segunda unidad del poema comienza otra vez con el verbo "negarse a": "Y me niego categóricamente / a dejar de hablar / mi lengua, mi acento y mi historia" (vv. 16-18). Hablábamos más arriba de la equivalencia desde el punto de vista argumentativo del adverbio "rotundamente" con otros utilizados por Campbell; ella utiliza el "categóricamente" con el mismo efecto de afirmación y de conciencia. Ahora bien, su radio de acción se traslada a un 
ámbito colectivo, cuyos trazos remiten a un patrimonio común. De la esfera individual pasamos a la colectiva dentro de un paralelismo sinonímico, en donde las equivalencias se suceden:

\section{INDIVIDUAL}

"a negar mi voz, mi sangre y mi piel"

(vv. 2-3)

\author{
COLECTIVO \\ "a dejar de hablar \\ mi lengua, mi acento y mi historia" \\ (vv. 17-18)
}

Con estas correlaciones, bien significativas: voz-lengua, sangre-acento, piel-historia, Campbell traza la historia de los afrodescendientes y de su problemática identitaria, para que sea esta parte del poema la explicitación de una reivindicación étnica, que desea terminar, de una vez por todas, con la historia de sufrimiento, de segregación, de subordinación, en una palabra, de racismo. Para ello, esboza todo un programa de rebelión ante el silencio ("los que callan", v. 20), el miedo ("los que temen", v. 21), el sufrimiento ("los que lloran", v. 22). Más allá de las anáforas y eufonías buscadas para que la musicalidad se despliegue, el poema de Campbell plantea tanto esa toma de conciencia como la rebelión que los adverbios enfáticamente reafirman dentro de ese paralelismo abiertamente buscado, de modo que se exprese ese renacimiento de sí misma, cuando la indagación de las raíces y la instrospección "give outward expression to the realities of black life" (Martin-Ogunsola, 2003, p. 424) ${ }^{8}$. La crítica especializada ha celebrado tanto esta perfección formal como la agenda ético-política que encierra el poema de Campbell: "Technique and content combine to make the poetry of Shirley Campbell increasingly important" (Gordon, 2003, p. 440)9 .

Andira Watson reconoce esta maestría poética del poema de su colega y establece ese diálogo de amistad y de sororidad con Campbell. Watson no solo escoge el mismo título estableciendo desde allí el reconocimiento intertextual de tal identificación, sino que tal operación ideológica continúa con la dedicatoria del poema. Ello hace que este caso de similitud de título no sea visto como un plagio de ningún modo ${ }^{10}$, sino como un homenaje-reconocimiento que la estrategia de comunicación refuerza, cuando el tú, destinatario del poema, se identifica con el nombre de Shirley; veamos la primera unidad del poema de Andira Watson:

Soy como vos Shirley

Rotundamente negra

Vivo $^{11}$ en Managua y

desayuno

(v. 5) rice and beans

green banana

bread fruit

ginger tea

black tea

(v. 10) La gente me ve blanca pero yo me siento negra. Negra como mi padre como mis primas

Negra como mi hermano

8 "ponen de manifiesto la realidad de la vida afrodescendiente".

9 "Técnica y contenido se combinan para hacer la poesía de Shirley Campbell cada vez más importante".

10 En el mundo de los derechos del autor, se vería de esta manera si no existe una autorización de su utilización.

11 No hay signos de puntuación en el poema, por lo que no es una errata. 


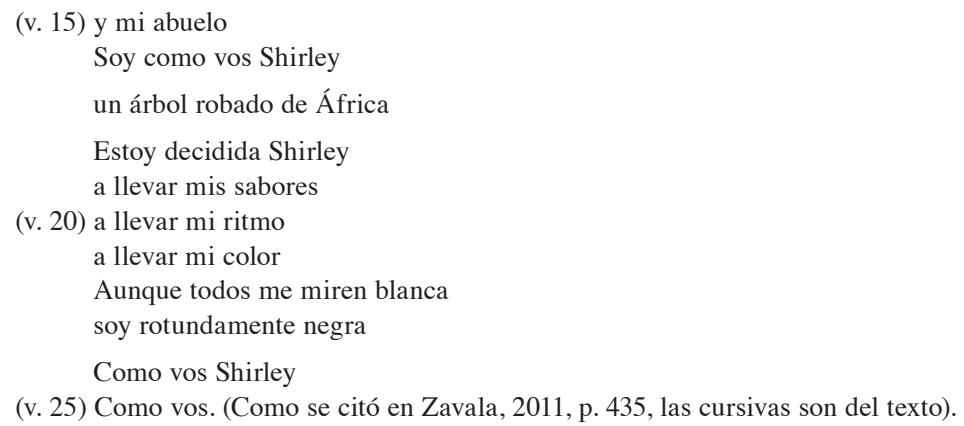

La afirmación de la identidad, en la frase categórica "Rotundamente negra" del verso 2, subraya la trabazón ética del programa de Andira Watson, al presentar a su voz poética como libre de esas ataduras a las que hacía referencia el poema de la poeta costarricense; en Andira Watson esta voz las reconoce y las asume en ese grito de combate y de afirmación étnica. La poeta nicaragüense comienza y conduce su reivindicación también al terreno de su biografía y circunstancia personal ("Vivo en Managua y / desayuno", vv. 3-4). "Si uno es lo que come", como indica la sabiduría popular, las señas de identidad se dirigen a unos platos y a unos alimentos que caracterizan el espacio atlántico o caribeño de Nicaragua, porque "tienen una función etnocultural, expresan identidad" (De Maeseneer, 2003, p. 57). No solo se reconoce en la cotidianeidad de unos rasgos culinarios que la individualizan, sino también los alimentos y las comidas mencionadas en inglés tienen el valor de la diferencia cultural de quien se reconoce con otros orígenes en el espacio caribeño inglés, pues el "ginger tea" y "black tea" (de los versos 8 y 9) vienen a explicitar una tradición que no es la hispánica. Tradicionalmente, este componente caribeño no se reconoce en el imaginario identitario nicaragüense, pues hace provenir la comida y su forma de prepararla oficial y solamente "de la mezcla exclusiva de aportes hispanos e indígenas" (Ramírez Mercado, 2007, p. 233). Por ello, las diferencias culinaria y alimenticia hacen emerger el conflicto que se dibuja en la identidad individual, ahora confrontada al espejo personal y a la imagen que recibe de los otros: "La gente me ve blanca / pero yo me siento negra" (vv. 10-11). Emerge, pues, ese conflicto que Sergio Ramírez Mercado planteaba en términos de un blanqueamiento de la identidad nicaragüense o un ocultamiento de sus raíces negras. En el poema se dibuja como un contraste percibido -aunque conlleva una negación así interiorizada- cuando se enuncia con una subordinación concesiva, que muestra ese obstáculo: "Aunque todos me miren blanca / soy rotundamente negra" (como se citó en Zavala, 2011, p. 435, vv. 22-23).

Se trata de un desfase entre esa percepción que poseen los otros y la representación de sí misma descubierta ahora en la recapitulación autobiográfica, de una "concienciación por medio de la memoria" (Ciplijauskaité, 1994, p. 38), para que opere en el poema una toma de conciencia liberadora, cuando la sangre o las raíces africanas se han diluido y se reivindique, en efecto, no solo el linaje de la familia, sino también los antepasados, en donde está encerrado el cuerpo de la memoria ancestral: "This symbolic linking of time joins the memory of the subject in the past, present and future" (Mosby, 2003, p. 184) ${ }^{12}$, con una fuerza de la que no puede sustraerse la voz poética. Ese es otro de los rasgos de esta identificación cultural.

12 "Esta vinculación simbólica del tiempo conecta la memoria del sujeto con el pasado, el presente y el futuro". 
Sin embargo, al subrayar el frondoso árbol genealógico, Watson enfatiza el desgarramiento que supuso realizar el viaje desde tierras africanas en forma de un trauma; la esclavitud se manifiesta en forma textual, cuando la sinécdoque del verso 17, "un árbol robado de África", así separado en forma magistral entre las estrofas, motiva tanto esa separación como esa hecatombe que incidió en las raíces primigenias del desarraigo y expulsión de su paraíso ancestral. El reconocimiento de esta injusticia y de sus avatares en el adjetivo "robado" es el punto de partida para una toma de conciencia personal y colectiva que en el poema de Campbell no se manifestaba explícitamente. Ahora bien, si es cierto que en materia de intertextualidad el poema de Andira Watson conecta y evoca el de Shirley Campbell gracias a sus relaciones textuales, su afirmación étnica las solidariza; pero es necesario ir más allá no solo de esta temática, sino también ante todo abordar su agenda política en tanto estrategia discursiva.

Watson asume esta realidad que la esclavitud generó y plantea ese punto de resolución con la forma verbal "estar decidida a"; así, es obvio que esa marca de género femenino señala su condición de mujer que repiensa su historia, sus orígenes y se compromete con su destinatario bajo los presupuestos de este mismo programa cultural: "Estoy decidida Shirley / a llevar mis sabores / a llevar mi ritmo / a llevar mi color" (como se citó en Zavala, 2011, p. 435, vv. 18-23).

El ritmo ahora se hace ternario, para que en la cadena metonímica los tres elementos configuren su adscripción y su apuesta por la identidad: "sabores" (v. 19) por cocina, "ritmo" (v. 20) por música y "color" (v. 21) por piel, permiten comprender la traslación de imágenes realizada por Watson y, de esta manera, se intensifica el pasaje de lo poético hacia lo ideológico. La "sororidad" se establece en dos pasos articulados en el poema. El primero se percibe en la concienciación tanto de la negación como de los silencios, en la medida en que tal "disposición mental" (Ciplijauskaité, 1994, p. 39) obliga a asumir su herencia biológica o colectiva en tanto memoria analítica: "La gente me ve blanca / pero yo me siento negra" (como se citó en Zavala, 2011, p. 435, vv. 10-11), "Aunque todos me miren blanca / soy rotundamente negra” (como se citó en Zavala, 2011, p. 435, vv. 22-23). El segundo consiste en un proceso de liberación individual, de un repaso de situación personal, para explotar con voz diáfana y potente en el verso "soy rotundamente negra" (v. 23).

La sororidad no es cuestión de una pose intelectual o de simple amistad de poetas, es una reivindicación que nace de la "negritud" de la piel y del cuerpo y estalla como reclamo al reformular la voz y el cuerpo del sujeto poético. Llama poderosamente la atención, en efecto, el punto de convergencia entre las dos poetas; el "Rotundamente negra", como podemos pensar aquí, es algo más profundo que enuncia, en tanto lección de vida, la agenda ético-política de ambas poetas afrodescendientes. Si en Campbell la forma verbal era, "me niego a", en cuanto rechazo y denuncia de una situación de marginalidad y de toma de conciencia, en Watson es "estoy decidida a", en cuanto proyecto de vida y de emancipación. Observemos cómo los dos poemas entran dentro de una articulación semántico-pragmático para después concretarse como coherencia ideológica:

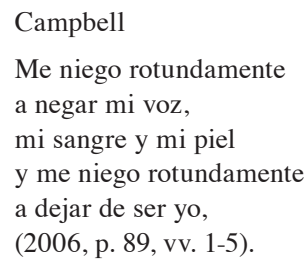

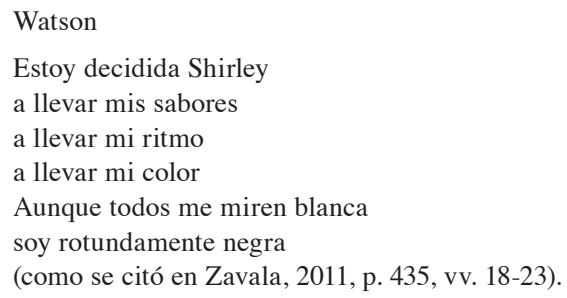


Cuando se colocan en forma paralela estas dos citas de los poemas en estudio, constatamos el diálogo y la sintonía de estilo y de tono reivindicativo de sendos poemas. Nos percatamos también de que pasamos de la reafirmación de la identidad personal en Campbell: "y me niego rotundamente a dejar de ser yo" (vv. 4-5) a la reivindicación del color de la piel y, por lo tanto, de la identidad étnica en Watson: "Aunque todos me miren blanca / soy rotundamente negra" (vv. 22-23). Allí en donde comienza Campbell, termina Watson con su reclamo de sororidad: "Como vos Shirley / Como vos" (vv. 24-25). La pluma y el color las une, en un despertar hacia una conciencia colectiva. La "sororidad", que se emplea siempre en un contexto de solidaridad ante la discriminación sexual de las mujeres, sigue teniendo su pertinencia y se actualiza en la respuesta exultante ofrecida por la nicaragüense Watson al poema de Campbell. Esos vasos comunicantes pasan por la mediación sensorial dentro de la interacción social, porque lo que pone en juego el cuerpo no está limitado a simple notaciones corporales, las rebasa imponiéndonos características sobre la construcción de la existencia y la colectividad; se trata de la "dimensión más arraigada en la intimidad del sujeto, la más impalpable [...], ya que drena el inmenso terreno de la sensorialidad" (Le Breton, 2002, p. 58). De la afirmación del cuerpo, nos trasladamos a unas percepciones sensoriales que dan contenido por su tono y un contorno a un despliegue más allá de lo corporal y fisiológico; cuando ponemos en paralelo sendos poemas, se acentúa aún más ese pasaje del color de la piel a una experiencia colectiva o a una dimensión humana e histórica:

Campbell
Reconocimiento del cuerpo
(vv. 1-15)
Reafirmación colectiva
Y me niego categóricamente
a dejar de hablar
mi lengua, mi acento y mi historia
y me niego absolutamente
(v. 20) a ser parte de los que callan
de los que temen
de los que lloran
porque
me acepto
(v. 25) rotundamente libre
rotundamente negra
rotundamente hermosa.
(2006, p. 89).

Campbell

Reconocimiento del cuerpo (vv. 1-15)

Y me niego categóricamente a dejar de hablar

mi lengua, mi acento y mi historia y me niego absolutamente

de los que temen

de los que lloran

(v. 25) rotundamente libre

rotundamente hermosa.

(2006, p. 89).

\author{
Watson \\ Reconocimiento del cuerpo \\ (vv. 1-9) \\ Reafirmación colectiva \\ La gente me ve blanca \\ pero yo me siento negra. \\ Negra como mi padre \\ pero yo me siento negra. \\ Negra como mi padre \\ como mis primas \\ Negra como mi hermano \\ (v. 15) y mi abuelo \\ Soy como vos Shirley \\ un árbol robado de África \\ Estoy decidida Shirley \\ a llevar mis sabores \\ (v. 20) a llevar mi ritmo \\ a llevar mi color \\ Aunque todos me miren blanca \\ soy rotundamente negra \\ Como vos Shirley \\ (v. 25) Como vos. \\ (como se citó en Zavala, 2011, p. 435).
}

Rita Catrina Imboden (2012) nos propone comprender el cuerpo como una frontera entre lo interior y lo exterior del sujeto, mientras que la piel sería esa puerta de acceso y de entrada hacia "figuras de la abundancia, del desbordamiento, de la tensión, la fecundación y el gozo" (p. 98). Para establecerlo de esta manera, hay que redefinir y modificar esa relación del cuerpo en la escritura poética y tanto Campbell como Watson lo consiguen haciendo que 
se sienta en el color de la piel una historia colectiva, porque el cuerpo habla en Campbell: "mi lengua, mi acento y mi historia" (v. 18); mientras que en Watson obliga "a llevar mis sabores / a llevar mi ritmo" (vv. 19-20). Además, y es significativo en estas poetas, la experiencia de lectura despliega un ritmo y una musicalidad que transforma el poema en un "cuerpo sensible" (Imboden, 2012, p. 53, las cursivas son del texto), abierto a la experiencia exultante y melódica, gracias, sobre todo, al ritmo, al verso breve y a toda la disposición estratégica que irradia el adverbio "rotundamente" y los otros adverbios.

Queda claro que el diálogo entre ambas poetas, más allá del estímulo de la amistad y de esa sintonía de almas gemelas que el tópico encerraba, es aquí la ponderación de una verdadera sororidad que hace que mujeres afrodescendientes se hermanen para reivindicar sus raíces ancestrales y sea el inicio de la asunción de la identidad. Vamos más allá de la afinidad de poetas o de la sensibilidad excepcional que las solidariza en la actividad literaria. Muy bien las puede caracterizar ese calificativo que Miriam DeCosta Willis utiliza como título del libro que ella edita: Daughters of the Diaspora, en donde se reafirma "aware of her blackness, of the significance of her colour and hair texture" (2003, p. XXIV) ${ }^{13}$. Se trata de un combate colectivo que abre el debate hacia un nuevo entendimiento con una pregunta básica: "[to return] frequently to the question of colour" (Gordon, 2003, p. 438) ${ }^{14}$, con el fin de mostrar su compromiso y celebrar esta comunidad de lazos así encontrada y revalorada. Las dos poetas, a las que podemos otorgar el título de "afrodescendientes", fraternizan con la esperanza última de una nueva comprensión en la que la tolerancia y una perspectiva multicultural ganen terreno en sus respectivos países, ante olvidos y desvaríos de sendas historias nacionales. Tanto Campbell como Watson reafirman esa necesidad de una herencia cultural que permita redefinir y reinterpretar lo que es tener una identidad de mujer a través del color de la piel y sus manifestaciones / expresiones culturales.

\section{Bibliografía}

Bourdieu, P. (1997). Las reglas del arte: Génesis y estructura del campo literario. (2 ed.). Barcelona: Editorial Anagrama.

Campbell, S. (2006). Rotundamente Negra. San José: Ediciones Perro Azul.

Castilla del Pino, C. (2000). Teoría de los sentimientos. (3 ed.). Barcelona: Tusquets Ediciones.

Ciplijauskaité, B. (1994). La novela femenina contemporánea (1970-1985): Hacia una tipología de la narración en primera persona. Barcelona / Santa Fe de Bogotá: Editorial Anthropos / Siglo del Hombre Editores.

Curtius, E. R. (2004). Literatura europea y Edad Media latina. (Tomo 2). México, D. F.: Fondo de Cultura Económica.

DeCosta Willis, M. (2003). Introduction: 'This Voyage Toward Words': Mapping the Routes of the Writers. En M. DeCosta Willis (Ed.), Daughters of the Diaspora: Afra-Hispanic Writers (pp. XVI-XLII). Miami: Ian Randle Publishers.

13 "consciente de su negritud, del significado de su color y de la textura de su cabello".

14 "[para regresar] una y otra vez a la cuestión del color". 
De Maeseneer, R. (2003). El festín de Alejo Carpentier: Una lectura culinario-intertextual. Ginebra: Librairie Doz.

Genette, G. (1987). Seuils. París: Éditions du Seuil.

Gordon, D. K. (2003). Shirley Campbell's Rotundamente negra: Content and Technique. Miriam DeCosta Willis (Ed.), Daughters of the Diaspora: Afra-Hispanic Writers (pp. 435-441). Miami: Ian Randle Publishers.

Imboden, R. C. (2012). Cuerpo y poesía: Procesos de presentificación del cuerpo en la lírica mexicana del siglo XX. Berna: Peter Lang.

Kirkpatrick, S. (1989). Las Románticas: Escritoras y subjetividad en España, 1835-1850. Madrid: Ediciones Cátedra.

Le Breton, D. (2002). La sociología del cuerpo. Buenos Aires: Ediciones Nueva Visión.

López-Casanova, A. (1994). El texto poético: Teoría y metodología. Salamanca: Ediciones Colegio de España.

Martin-Ogunsola, D. (2003). 'Patches of Dreams': The Birth of Shirley Campbell's Oeuvre. En M. DeCosta Willis (Ed.), Daughters of the Diaspora: Afra-Hispanic Writers (pp. 424-440). Miami: Ian Randle Publishers.

Matas Caballero, J. (2001). El petrarquismo en los poetas novohispanos del cancionero Flores de Baria Poesía. Estudios Humanísticos. Filología, (23), 75-98.

Mosby, D. E. (2003). Place, Language, and Identity in Afro-Costa Rican Literature. Columbia: University of Missouri Press.

Ramírez Mercado, S. (2007). Tambor olvidado. San José: Grupo Santillana de Costa Rica.

Real Academia Española. (2014). Rotundamente. En Diccionario de la Lengua Española (23 ed.). [Versión digital]. Recuperado de https://dle.rae.es/rotundamente.

Rotundus. (1980). En Diccionario ilustrado Latino-español, Español-latino (13 ed., p. 443). Barcelona: Vox.

Sánchez-Blanco, F. (1992). Una ética secular; la amistad entre los ilustrados. Cuadernos de Estudios del Siglo XVIII, (2), 97-115.

Zavala, M.(2011). Con mano de mujer: Antología de poetas centroamericanas contemporáneas (1970-2008). Heredia: Fundación Inteartes. 